\title{
Scoliosis manager for physiotherapist. An internet free tool to help in treating scoliosis patients with exercises
}

\author{
Michele Romano*, Alberto Negrini \\ From 7th International Conference on Conservative Management of Spinal Deformities \\ Montreal, Canada. 20-22 May 2010
}

\section{Background}

The coservative treatment based on exercises is the main therapeutic strategy widely used for patients affected by scoliosis not particularly important and as a supporting tool in case of prescription of brace. The specific exercises are furthermore means of treating scoliosis in adults, in order to reduce pain and to contrast the progression of the curves. According to SEAS approach the specifity of scoliosis exercises comes from the combination of the specific Active Self-Correction (ASC) required by each single patient with the pathological and individual functional needs. Accordingly, a big set of exercises can be considered, once individual ASC is known and applied.

\section{Materials and methods}

Starting in 2003, a software has been developed to manage the exercise programs that are prescripted to scoliotic patients.

Initially, the program should had to group the exercises in "sessions" (195 sessions), that means that several exercise groups were available for the patients to be performed, on the basis of the typology of the curve and the treatment phase (1st session, 2nd session etc.)

Afterwards, the exercises have been organized in "groups" (505 groups) to permit the therapist to select the most appropriate exercise to each single patient. These exercises are structured tree-like within a database where the trunk of the tree is represented by the area of the body to be treated (lumbar spine, shoulders, knee etc.) followed progressively by the aim that has to be performed (mobilization, stabilization, stretching) the direction of the movement (flexion, rotation etc.) and the position (lying, standing, sitting etc.) to be assumed by the patient.

Actually, the program includes a database of 1300 different exercises.

Hence, the program has been integrated with a schedule of several tests of assessment in order to choose more easily the exercises. Specific tutorial to learn and chose the correct ASC are included.

In the end it was completed with a clinical diary and the twin-software used by the physicians for the medical examination.

\section{Results}

Since testing started in January 2003, the software was used for the planning of 11652 different exercise programs for 3432 different patients treated.

Actually it is used in 5 different centres in Italy by 20 therapists.

\section{Discussion}

We are convinced of the necessity that a community has to established who shares the non-operative treatment purposes of scoliosis and who contributes to the development of a working tool more and more efficient that helps the less experienced operators to treat this pathology. For that purpose, a simpler version of this software has been created, to be used freely in the web, with a guided composition course of the exercise programs and supplied with a list of tutorials that permit to achieve

ISICO (Italian Scientific Spine Institute), Milan, Italy

Full list of author information is available at the end of the article 
the essential notions for the choice and for the correct teaching of the selected exercises.

Published: 10 September 2010

doi:10.1186/1748-7161-5-S1-028

Cite this article as: Romano and Negrini: Scoliosis manager for

physiotherapist. An internet free tool to help in treating scoliosis

patients with exercises. Scoliosis 2010 5(Suppl 1):O28.

Submit your next manuscript to BioMed Central and take full advantage of:

- Convenient online submission

- Thorough peer review

- No space constraints or color figure charges

- Immediate publication on acceptance

- Inclusion in PubMed, CAS, Scopus and Google Scholar

- Research which is freely available for redistribution

Submit your manuscript at www.biomedcentral.com/submit 